show lower average AAP contributions (per-week) than would a group with a shorter stay.

It is particularly unfortunate that focused interoiews held in London, Winnipeg and Regina were not also held in other communities in order to shed light on whether the felt-impressions of refugees themselves squared with those expressed by host-group co-ordinators and CEC counsellors. In the communities without such interoiews, information on social adaptation is derived exclusively from seroice workers, not from refugees.

\section{Conclusion}

Government-assisted refugees who participated in the Host Group Program showed a very positive trend in terms of language acquisition and frequency of use of the English language. There was also an indication of lower drop-out rate among the host-group refugees. In the longer term, language acquisition was, and is expected to result in higher levels of employment and generally more successful settlement.

Very few in the matched group have relocated to other communities since their arrival. Most of the matched group developed Canadian friends and acquaintances. These factors indicate a higher level of integration into the community for the host group as compared with the control group.

In terms of AAP payments to refugees, differences between hosted and control groups were slight with payments to hosted refugees being slightly less overall, even though the duration on AAP benefits may have been longer. In several communities the proportion of refugees who found employment within 12 months after arrival was greater among those with Host Group experience.

Reports from the CEC's and Host Group co-ordinators illustrate clearly that the Project is increasing community awareness of the refugee situation. This effect will have a positive impact on how all immigrants are accepted by Canadians, which in turn will be reflected in the immigrants' increased ability to integrate into and contribute toward the development of Canadian society. We invite you to share with us some of those reports in a following article, and to consider as you read, the human scale of Canada's commitment to refugees.

\title{
A Canadian Concern
}

\author{
Noreen Spencer-Nimmons
}

Recently we invited the Host Program co-ordinators in organizations across Canada to send statistics, their annual evaluation, and any other information they cared to provide about the program and their work. They sent statistical data braced with substantive human interest "Reflections" or "And next year" items. Overall, we have learned that coordinators, staff and volunteers are concerned individuals who are committed both to the Host Program and to its recipients; they follow specific criteria established by the Policy and Planning Division, Settlement Branch of Employment and Immigration Canada; and they receive help from those employed in other government proǵrams which assist newcomers, such as the Immigrant Settlement and Adaptation Program (ISAP) and the Adjustment Assistance Program (AAP). Moreover, it was apparent that staff and volunteers in the Host Program frequently add their own ingenuity in terms of 'getting the program started and keeping it going.' Finally, co-ordinators networked with each other about special humanitarian concerns, shared experiences, and pragmatic suggestions regarding both the positive and negative factors affecting either the Program or their work. This article approaches the program from its operational bases in Canadian communities and shares with our readers both the concerns and commitment of those involved.

\section{Refugees and Hosts: Needs and Resources}

Refugees endure the trauma of a sudden uprooting from homeland, even as they face the necessary and often formidable task of finding employment, settling into everyday life and adapting to the Canadian culture. Assistance with these needs is given by Host Program organizations and volunteer 'hosts' in cities across Canada. Since 1985, they have been receiving and assisting refugees from diverse ethnocultural, linguistic, religious and national backgrounds. Refugees came from Afghanistan, Bulgaria, Cambodia, Chile, Czechoslovakia, El Salvador, Ethiopia, Hungary, Iraq, Iran, Libya, Nicaragua, Poland, Romania, Uganda, and Vietnam. Their many talents and skills included: accountant, accounting clerk, bookkeeper, bricklayer, computer programmer, computer operator, childcare worker, dress designer, farmer, keypunch operator, loom mechanic, salesperson, seamstress, tailor, teacher, and typist.

Government-sponsored refugees are met upon arrival by an official from the Immigrant Settlement and Adaptation Program (ISAP) who, among other duties, will determine whether a 'host' is needed. Frequently a Host Program Coordinator is part of the initial reception procedure. The immediate services with which the newcomers needed assistance were listed by Aleta McKim, Coordinator of the Yorkton, Saskatchewan program: housing, employment, English studies, shopping for food and clothing, familiarization with the city and help with transportation, socialization, friendship and support, sponsorship of family members, gardening, and recreational activities. Kitchener Host Program Coordinator Anna Czesniak adds: translation at medical appointments, assistance with school registration, budgeting, and learning about Canadian culture.

Welcome Houses or Refugee Reception Residences exist in many communities across Canada. Last year the London group worked to achieve the "Refugee Transition House." In Vancouver, the I.S.S. Welcome House is located at 536 Drake Street (see picture), and in Kitchener, the Refugee Reception House is a gracious old home, purchased by the Mennonite Church and the House Church Assembly. Similar to other Welcome Houses, it is partially funded by the Canada Employment Centre (CEC). Located downtown, it has 11 bedrooms and can accommodate 23 people at a time. In this home, as in others, initial orientation is given. The average stay for refugee newcomers is three weeks, prior to the move into their own apartment or flat.

Matching the newcomers with Host Family volunteers is a process which begins, ideally, between 2 to 4 days after the refugee arrives. Matching is based on the following criteria: need, gender, age, a 
single refugee, a family, and language capabilities. Margery Solomon, Coordinator at the International Centre, Citizenship Council of Manitoba, advises that for those refugees who have no contacts in Canada, priority is given first to "families, then to single women and then single men. However, if a request for a host group is made by someone not considered a priority, volunteer hosts are provided." And the needs of a single female household head with children are given special consideration.

But not all refugees need a Host Family to assist in their settlement. This occurs amongst many Polish refugees who are taken immediately into the Polish communities in Canada. And in Manitoba, Margery Solomon, advised us that,

\begin{abstract}
It has been our experience in Winnipeg, that if family or friends are being reunited, volunteers, however wellintentioned, are sometimes seen as intrusive. This can have a negative effect on both the newcomers and the volunteers.
\end{abstract}

Program co-ordinators listed the following sources from which community support is contributed: church groups, individual volunteers, neighbourhood associations, ethnic groups, people who had hosted before, word of mouth, Universities, College Spanish classes and schools, those who were refugees, volunteer placement services, hospitals, public (media) attention, and the ' $Y$.'

Volunteer hosts are interviewed, either in groups or individually. They receive background reading material, a job description list, a guide and Refugee Host Family Summary, and they receive training. Awareness and training sessions are conducted by program co-ordinators and their staff. Items discussed in detail are culture shock and the importance of learning English as a cure,' and ways in which hosts can help 'create independence,' thereby reducing the newcomer's stress and sense of loss of control over his or her life. Training begins with an orientation on the matching procedure, details of a refugee's settlement, first priorities in settlement needs in the first year and how the host can help. When matching occurs, the refugees receive a pamphlet (written in their language) which explains

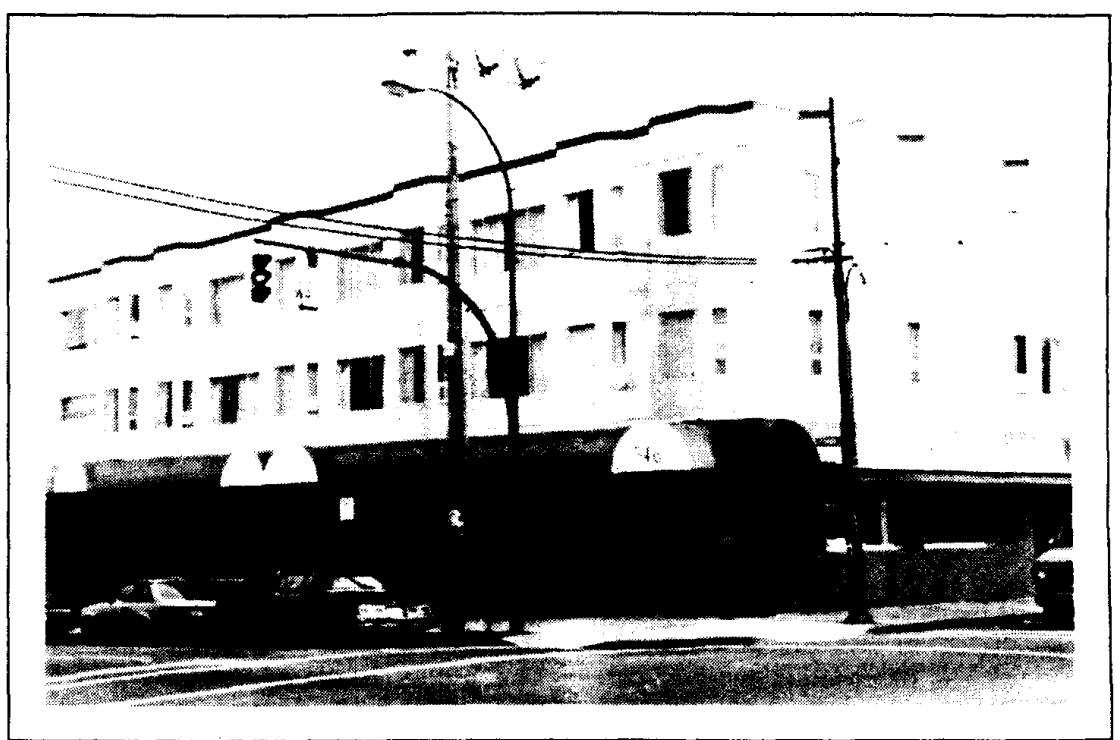

the Program; hosts receive a cultural profile of the refugees whom they will be assisting.

The "match-maker" co-ordinator will choose the most appropriate host and introduce the two groups to each other. Co-ordinators stay with the groups and maintain contact because the refugee newcomers are shy and tense. Evelyn Meyer, Host Program Co-ordinator at the Windsor-Essex County Family YMCA states that, "it is important to help create a relaxed atmosphere. Sometimes volunteers feel shy and they tell me they appreciate my presence. Both newcomers and volunteers then feel comfortable about contacting me thereafter." Joyce Kyi, Executive Director of the Immigrant Services Society (I.S.S.) of British Columbia writes:

Two I.S.S.staff members devote full time to the Host Program. They recruit, orient and train Canadian volunteer hosts, and 'match' them with refugee family units or individuals. Every effort is made to match families with families; for example, refugees with young children are matched where possible with Canadian families with young children. When kids get together on a happy basis, the elders often follow suit. Similarly, individual refugees are often matched with individual hosts.

Enlisting Host Family volunteers is an ongoing product of publicity and successful public relations with community groups and individuals. Forms of media presentation, collated from the crossCanada reports from co-ordinators are: monthly newsletters sent to clients and volunteers; newspaper articles which include data on the refugee determination procedure, and human interest stories which inform and sensitize the general public; information packages; volunteer presentations at community meetings, Masses and church group activities, and on local and national TV or radio programs.

Everywhere in the Host Program the importance of the co-ordinator's experience was evident, particularly in developing a deeper understanding of the refugee's home country culture and communicating that to volunteers. Coordinators work diligently and creatively at the public relations aspect of their work. Sensitizing Canadian children in schools, for example, was found to be an important method of breaking down barriers which impede the settlement process of refugee families, especially that of their children. In London, the Host Family Co-ordinator's teaching background was invaluable for her separately prepared presentations to the Primary (Grades 1-3) and Junior-Senior Levels (Grades 4-8). In the latter group she developed the theme "Who is An Immigrant?" then, listing all of the countries that were represented in the classroom to stimulate discussion, she introduced the title 'Canada is a Land of Immigrants' and asked: "How does a refugee differ from an immigrant?"' The students' responses revealed a variety of misconceptions about refugees; these were openly discussed. The life of refugees in London (both those with a host and those without) was also discussed. An innovative idea was introduced to the students:

Cont'd on page 8 


\section{A Canadian Concern.... Cont'd from page 7}

form mini-host groups to welcome newcomers who arrive at your schools. The idea received a positive response: "At least $80 \%$ of every class want to host." A follow-up with the teachers was planned and, in general, it was agreed that working in the school system to break down prejudices was an important area of public relations.

\section{Benefits and Shared Concerns}

Common to all the reports sent in are the perceived benefits of the Host Program: the psychological and practical support which refugee newcomers receive; cultural insights gained by both refugees and host volunteers; and a more sensitive and informed public.

In Vancouver, Co-ordinator Joyce Kyi reports that "friendly contact ....and a feeling that one has a friend to give advice and sympathetic understanding can go a long way to relieving the sense of loss or the depression that is so often felt by refugees... and friendly advice (on priority needs) can alter the outlook of many a bewildered soul."

The Windsor-Essex County Co-ordinator of the Host Program adds that the Federal Government recognizes the potential for better-adjusted and quicker settlement for newcomers through this Pilot Project Program. The role of Host Family group volunteers is essential to the program particularly because of the exclusive attention which they can give to a refugee individual or family.

It is true that hosts can help with job contacts and provide a non-threatening audience for language practice. In one case, a host volunteer provided a job in his factory for the Cambodian man he hosted. In all other cases I am aware of in Windsor, host support was equally important but less direct. Hosts gave newcomers help in preparing resumes, filling out job applications, and by identifying factories and firms in the community who were accepting applications, etc. Success in getting a job was aided by the advice hosts gave for creating a good impression with potential employers: be on time, dress appropriately, shake hands, make eye contact, shave (only Don Johnson can get away with the twoday's stubble look,) and show yourself to be interested in work and eager to work diligently. Volunteers also give emotional support and friendship of a social nature.

Evelyn Meyer, Co-ordinator
In Winnipeg, Margery Solomon reported that:

We have no doubt that the friendship and assistance of their host group makes the transitional period much easier for newly arrived refugees. Almost as important is the first-hand knowledge gained by volunteers of the hardships and difficulties which the refugees have faced. It is extremely important that mutual understanding is achieved between neucomers and the communities in which they will settle. The Host Program is an excellent vehicle to help promote this understanding.

\section{Unmet Needs and Fears}

The unmet needs of refugees and the fears of the hosts present problems to be resolved. It is not unreasonable to expect that problems would exist, given the sudden uprooting of peoples and the urgency of their settlement needs, the compressed time factor in 'forced or involuntary migration' today, as compared with the slower pace of receiving past 'immigration groups,'and because of the diverse ethnocultural, linguistic and occupational backgrounds of both host volunteers and refugees. But problems are continually under review and solutions sought. Persistent striving toward success has become a testimony of the mutual concern of the government and private sector Program staff and volunteers, and of the refugee newcomers to Canada.

Of immediate concern to refugees as the most difficult aspects of adjustment, according to the Kitchener survey, were: lack of English, lack of money, homesickness, housing, adjusting to culture, unemployment, climate and 'feeling like foreigners.' Other co-ordinators added to this list: problems of communication, the unanticipated expectations of refugees, dealing with their sense of loss of control, and their basic need to 'settle down.' Reducing these fears and needs is a priority concern for both the government and private sector enablers.

One of the most important needs is getting a family settled. Consider, for example the case of a refugee family with children ranging in age from 5 to 15 years who have been 'in orbit,' mistakenly placed in detention, then been long in transit, and finally, upon arrival placed in a 'temporary hotel.' Parents and volunteers alike search for a positive answer to the childrens' plea: "Mama, WHEN can we unpack?"
Getting a job, particularly one for which their talents and skills are suited, is a fear experienced by most refugees. In many cases suitable employment remains an unmet need for both the refugee and the Host Family volunteer. In Vancouver, for example, it was reported that,

Hosts are able to help in most areas of settlement [except] to find employment during the first year in Canada. A reason for this is that there is a waiting period of approximately three to four months before they can enrol for English language training. The course itself occupies five months, so that only about three months remain of the first year in which Hosts (or Settlement Agencies) can help refugees to find employment.

The Manitoba Program staff experienced the problem that "no philosophy existed as to how matches should be made. Refugees were introduced to host groups as they became available with very little investigation of need. Another concern was that matches were often made several weeks after the newcomers arrival, leaving them without a community contact [personal support system] during the period when they needed it most."

In Yorkton, Saskatchewan, despite the best intentions of both groups, a breakdown occurred between the newcomers and hosts. Invited to a barbeque supper, the newcomers stated: "I am meeting you." This was interpreted by the Host Family volunteers to mean that they would all meet at the party. In fact, the refugee family was very proud to have purchased a second-hand car and intended to meet their hosts and drive them to the party. The refugee family arrived late and frustrated.

Sometimes the expectations of refugees can be frustrating to hosts, as the following report indicates:

Often clients feel that their Canadian hosts will be able to ensure that family members will be brought to Canada to join them. They do not realize that the procedures are the same for Canadians and immigrants... and that we can't do anything about it.

Compassion fatigue, the conflict of government assistance programs versus government refugee determination processes [and bills], and conflict amongst the volunteer sector should be added to the list of problems for which resolutions are sought. Joyce Kyi reported from Vancouver that recruit- 
ment for volunteers was not easy at first,

one reason for this was that church groups in particular, and other community agencies, had expended much effort over the Vietnamese 'Boat People' and needed time for respite and renewal of resources. Later, the adverse publicity generated by the arrival in Canada of "illegal claimants" to refugee status somewhat soured public opinion. The I.S.S. Host Program set out to counteract these factors by special efforts to educate local communities to the need of helping Government-assisted refugees, and to explain the definitions of "refugee" and "refugee claimant" and to outline the screening process for those accepted by Canada.

Across Canada, Community Coordinators reported that "the ongoing debate and protest of Canada's latest refugee policies is having a direct effect on the Host Program." Further, the advent of Bills C-55 and C-84 created an unanticipated backlash which affected refugees and volunteers alike. Community coordinators reported that when these Bills came under fire, volunteers were divided into "camps of those for... and those against' and this means either refugees or the government in general; but it is the Host Family Program in particular that suffers.

Canadian immigration officers were presented as unsympathetic and incompetent to ascertain who is a real refugee... and several people in this public open forum included people who are a hindrance to the Host Program...this affected host groups who recently told me that they were 'putting everything on hold' because they intend to get involved in sponsorship....and the Host Family Program statistic will no longer be important.

A few parishes or congregations who were once involved in the Host Program have stated that since the advent of the Bills they will now only be involved in sponsorship programs because they perceive this to be the only necessary government project. Yet, as one staff person stated, 'those advocates of accepting at least 40,000 refugees $a$ year and similar suggestions should also be in the front lines helping secure housing, jobs, and moral support. Talk is cheap...action is vital.'

One community reported that volunteer support has come almost exclusively from Church contacts and that other social groups tend to need volunteers for their own charity projects.
The Council is fragmented and not a unifying or supportive presence. The ethnocultural groups have not been approached about the Host Program because local council jealously guards the names of contact members...I do not know if the established groups would respond to the program... and take newly arrived people under their wings.

Determination and fatigue are sensed in reports from other communities. A first attempt at having Canadian host group families board single refugees was not as successful as had been hoped, "but [we] will try again...because the housing problem would be eased and socialization would be increased if we could get the idea across." Another community stated,

the biggest complaint I hear is 'what do we do about volunteers who don't stay involved in visiting the family after the first few months. The newcomers interpret this as persqnal rejection'.... and another person involved in the program added that 'other people in my group go to visit or whatever if I call them but I'm tired of having to remind them all the time.

\section{The Future}

All the letters and reports received from Host Program Co-ordinators across Canada addressed the future, and they substantiated the fact that only a committed 'community' will assess unmet needs and concerns and be flexible enough toward their resolution, for the future benefit of all parties involved in the settlement process. The Host Program is uniquely Canadian in terms of the symbiotic relationship that does exist between the government and the private sector for settlement assistance to the refugee newcomers.

In Kitchener, Jonquil Brunker, Director of Newcomer Services, stated that the community was responding well through meaningful volunteer involvement, and that:
Challenges ahead include organizing ser- vice and member-based clubs to consider the Host Program as an avenue for com- munity service. Re-energizing past hosts and linking settled families with new arrivals will continue to be part of the work. The program provides a model in volunteer development and has made profound changes to the lives of many Canadian families. The most obvious benefit of the program is the qualitative improvement in the settlement of newly arrived government-sponsored refugees.

Vancouver reported that the efforts of bringing volunteer hosts into the refugee newcomer's settlement process had produced lasting relationships, and a growing knowledge and appreciation of other cultures among Canadians as well as in the adaptation of the newcomer to our 'way of life.'

The success of the Host Program should be measured in human terms, and not in quotable figures...in this third year lof our Host Program involvement] the mandated 100 "matches" was greatly exceeded: 164 hosts were matched with refugee family units.

London and Windsor stated that "the future prospects for the Host Program will always include a core of extremely dedicated volunteers who come from churches." And it will be necessary to find a way to unite various groups who are separately helping refugees. "Cooperation rather than competition could result in a more productive settlement rate for the refugees because the Host Program remains a very worthwhile and important project."

Combatting racism and protecting 'new' refugee groups in the future was realistically addressed in one community when it was felt that "arrivals in April of this year verify the expectation that refugees from Africa will be the majority for the foreseeable future. Host groups will be required to give a much greater degree of support for these 'visible' refugees and their commitment to the program will be tested." Still, concern was positive:

We have no doubt that the friendship and assistance of the host group makes the transitional period much easier for the newly arrived refugees. Almost as important is the first-hand knowledge gained by volunteers, of the hardships and difficulties which the refugees have faced. It is extremely important that mutual understanding is achieved between newcomers and the communities in which they will settle, and the Host Program is an excellent vehicle to help promote this understanding. However, care must be taken to ensure that both the volunteers and the newcomers have a positive experience if we hope to continue to find a sympathetic response to the program in our community.

Elsewhere in Canada, Co-ordinators or Executive Directors reported that their programs had grown steadily in strength and that they were certain of its usefulness, not only in aid of the refugees, but

Cont'd on page 10 